\title{
Bronchial asthma is associated with increased risk of chronic kidney disease
}

\author{
Hui-Ling Huang ${ }^{1,2}$, Shinn-Ying Ho ${ }^{1,2}$, Chien-Hsun Li ${ }^{1,3}$, Fang-Ying Chu', Li-Ping Ciou1, Hua-Chin Lee', \\ Wen-Liang Chen ${ }^{1,2}$ and Nian-Sheng Tzeng ${ }^{4^{*}}$
}

\begin{abstract}
Background: Bronchial asthma influences some chronic diseases such as coronary heart disease, diabetes mellitus, and hypertension, but the impact of asthma on vital diseases such as chronic kidney disease is not yet verified. This study aims to clarify the association between bronchial asthma and the risk of developing chronic kidney disease.

Methods: The National Health Research Institute provided a database of one million random subjects for the study. A random sample of 141064 patients aged $\geq 18$ years without a history of kidney disease was obtained from the database. Among them, there were 35086 with bronchial asthma and 105258 without asthma matched for sex and age for a ration of 1:3. After adjusting for confounding risk factors, a Cox proportional hazards model was used to compare the risk of developing chronic kidney disease during a three-year follow-up period.
\end{abstract}

Results: Of the subjects with asthma, 2196 (6.26\%) developed chronic kidney disease compared to 4120 (3.91\%) of the control subjects. Cox proportional hazards regression analysis revealed that subjects with asthma were more likely to develop chronic kidney disease (hazard ratio [HR]: 1.56; 95\% Cl: 1.48-1.64; $p<0.001$ ). After adjusting for sex, age, monthly income, urbanization level, geographic region, diabetes mellitus, hypertension, hyperlipidemia, and steroid use, the HR for asthma patients was 1.40 (95\% Cl: 1.33-1.48; $p=0.040)$. There was decreased HRs in steroid use (HR: $0.56 ; 95 \%$ Cl: $0.62-0.61 ; p<0.001$ ) in the development of chronic kidney disease. Expectorants,

bronchodilators, anti-muscarinic agents, airway smooth muscle relaxants, and leukotriene receptor antagonists may also be beneficial in attenuating the risk of chronic kidney disease.

Conclusions: Patients with bronchial asthma may have increased risk of developing chronic kidney disease. The use of steroids or non-steroidal drugs in the treatment of asthma may attenuate this risk.

Keywords: Bronchial asthma, Chronic kidney diseases, National Health Insurance Research Dataset

\section{Background}

Bronchial asthma is a chronic inflammatory lung disease with exacerbations, which may be a factor in its morbidity and mortality. The Global Initiative for Asthma (GINA) 2004 report states that nearly 300 million people suffer from asthma worldwide [1,2] and asthmatic patients in Taiwan account for $2.6 \%$ [1]. The report also states that urban living [3] and lower income [1] are risk factors for asthma and that the environment, regardless of indoor or outdoor, also impacts on patients with asthma [3].

\footnotetext{
* Correspondence: pierrens@mail.ndmctsgh.edu.tw

${ }^{4}$ Department of Psychiatry, Tri-Service General Hospital, School of Medicine and Student Counseling Center, National Defense Medical Center, \#325, Sec 2, Cheng-Gong RdNei- Hu District, Taipei City, Taiwan

Full list of author information is available at the end of the article
}

Bronchial asthma also influences other chronic diseases involving the cardiovascular and carbohydrate metabolism systems. Patients with asthma have higher risks of coronary heart disease (CHD) [4], diabetes mellitus [5], and hypertension [3], although the impact of asthma on other vital organs are not yet verified.

Chronic kidney disease (CKD) is a major global problem. Patients who progress to end-stage renal disease (ESRD) need dialysis or transplantation, which cause heavy medicoeconomic burden. In 2010, there were 651000 patients with ESRD in the United States whose care cost around US $\$ 28.3$ billion. In Taiwan, there were approximately $11.93 \%$ with CKD, about one eighth for Taiwanese. Recent studies have found that predictors of CKD include metabolic syndrome [6], obesity [7], vascular diseases [8], hyperlipidemia 
[9] and cardiovascular diseases [10], hypertension [11], diabetes mellitus [11], and heart disease [12] (OR: 1.95 [1.32-2.87]). However, there is no report on the association between asthma and kidney diseases.

This study used the Taiwan National Health Insurance Research Database (NHIRD) to determine the association of asthma and CKD in a three-year follow-up period (2003-2007). The National Health Insurance (NHI) Program, began in Taiwan in 1995, had enrolled 22928190 people as of June 2009, exceeding 99\% of the population. The NHI also has a contract with $97 \%$ of the medical providers in Taiwan [13]. The diagnostic coding used for the NHI in Taiwan is according to the International Classification of Diseases, 9th Revision, Clinical Modification (ICD-9-CM) diagnostic criteria [14]. Each diagnosis of asthma was made by board-certified internists, clinical immunologists, pulmonologists, or other medical experts. The Bureau of National Health Insurance randomly reviews the charts of 1 per 100 ambulatory and 1 per 20 in-patient claim cases to verify the accuracy of the diagnosis [15]. In Taiwan, the diagnosis of CKD follows the criteria of "Kidney Disease: Improving Global Outcomes (KDIGO)". CKD is defined as kidney damage as albumin-to-creatinine ratio $>30 \mathrm{mg} / \mathrm{g}$ in two of three spot urine specimens or glomerular filtration rate (GFR) $<60 \mathrm{~mL} / \mathrm{min} / 1.73 \mathrm{~m}^{2}$ for 3 months or more, irrespective of the cause [16]. The diagnosis of bronchial asthma bases on characteristic clinical history such as intermittent breathlessness, wheezing, troublesome night time cough and chest tightness, aided by lung function tests in some cases $[17,18]$, which is similar to criteria of the Global Initiative for Asthma (GINA) guidelines [19,20].

\section{Methods}

\section{Population data}

This research used the Longitudinal Health Insurance Database (LHID) 2005 derived from NHI program [21]. The LHID covered more than 25 million Taiwanese, or approximately $98 \%$ of the citizens [22] who lived in Taiwan more than four months.

The longitudinal database was a subset of the National Health Insurance Research Database (NHIRD) and consisted of 1 million Taiwanese enrolled in the database in 2005 [23]. It contained home care visits, ambulatory care, out-patient care, prescription drugs, and medical record that was encoded by using the International Classification of Disease, 9- revision, Clinical Modification (ICD-9-CM) [24].

The Internal Review Board encrypted the database to remove any personal identification before the release of the dataset for public access. In this study, both the study and control cohorts had no significant difference in sex and age distribution and were selected randomly from LHID2005. Patients aged $\geq 18$ years old who were first diagnosed with asthma (ICD-9-CM: 493) between January 1, 2004 and the end of 2007 were included in the study cohort and their date of diagnosis was their index date. The control cohort consists of the patients having no history of bronchial asthma or CKD from 2000 to 2010. These patients were randomly chosen by matching the gender and age of the study cohort with a ratio of 1:3. In addition, the middle date of the same month with that of the index date in the study cohort was assigned to the index date of the corresponding patient in the control cohort.

The patients were followed-up for three years from the index date until the patient was diagnosed with CKD (ICD-9-CM: 580, 581, 582, 583, 584, 585, 586, 587, 588, 589, 753, 403, 404, 2504, 2741, 4401, 4421, 4473, 5724, 6421 , and 6462) or until the end of 2010. Patients with missing data were excluded, as well as those with CKD before asthma. The final study and control cohorts had 35086 and 105258 patients, respectively. The follow-up interval of the subjects and controls for developing chronic kidney disease during is in a three-year followup period.

The covariates considered included diabetes mellitus (ICD-9-CM 250, 357.2, 362.0x, and 366.41), hypertension (ICD-9-CM 362.11, 401.x-405.x, and 437.2), hyperlipidemia (ICD-9-CM 272.x), heart disease (ICD-9-CM 410-429 and A codes A270, A279-A281, and A289) and obesity (ICD codes: 278.00, 278.01, 278.02, 278.03). Data on intake of steroids, anti-asthma drugs, and other drugs like expectorants, bronchodilators, anti-muscarinic agents, and airway smooth muscle relaxants, were collected.

\section{Ethical approval}

The Institutional Review Board of Changhua Christian Hospital approved the study (IRB/CCH, No. 121007).

\section{Statistical analysis}

The SPSS software version 19.0 (SPSS Inc., Chicago, IL, USA) was used for all statistical analyses. The chi-square test was used for the descriptive analyses concerning distribution of population, level of urbanization (i.e., provinces, counties, districts, and urban villages), geography (northern, central, southern, and eastern), income $(<18000$, between 18000 and 35000 , and $\geq 35000$ ), co-morbidities (e.g., diabetes, hypertension, hyperlipidemia, and heart disease) and medications.

Multiple logistic regression analyses were performed to estimate hazard ratio (HR) and 95\% confidence intervals (CIs) of bronchial asthma associated with CKD after controlling for age, sex, levels of urbanization and income. Statistical significance was set at $p<0.05$. 


\section{Results}

The asthma subjects $(\mathrm{n}=35086)$ and non-asthmatic controls $(\mathrm{n}=105258)$ both had a mean age of 47.72 years (Table 1). There was no significant difference in distributions of sex, age, urbanization, geography, and economic status between the two groups. The patients with asthma had higher prevalences of diabetes mellitus, hypertension, hyperlipidemia, heart disease and obesity compared to the

Table 1 Distribution of sex, age, urbanization, geography, income, co-morbidity, and medication of individuals with asthma and without asthma

\begin{tabular}{|c|c|c|c|}
\hline \multirow[t]{2}{*}{ Characteristic } & \multicolumn{2}{|c|}{ No. (\%) of individuals } & \multirow[b]{2}{*}{$p$ value } \\
\hline & $\begin{array}{l}\text { With asthma } \\
n=35086\end{array}$ & $\begin{array}{l}\text { Without asthma } \\
n=105258\end{array}$ & \\
\hline Age, yr, mean (SD) & $47.72 \pm 17.73$ & $47.72 \pm 17.73$ & 1 \\
\hline \multicolumn{4}{|l|}{ Sex } \\
\hline Male & 15460 (44.1\%) & $46380(44.1 \%)$ & \\
\hline Female & 19626 (55.9\%) & 58878 (55.9\%) & \\
\hline Age Group & & & 1 \\
\hline $18-29$ & $6534(18.6 \%)$ & 19602 (18.6\%) & \\
\hline 30-39 & $6307(18.0 \%)$ & $18921(18.0 \%)$ & \\
\hline $40-49$ & $6411(18.3 \%)$ & 19233 (18.3\%) & \\
\hline 50-59 & $5751(16.4 \%)$ & $17253(16.4 \%)$ & \\
\hline$\geq 60$ & $10083(28.7 \%)$ & 30249 (28.7\%) & \\
\hline Urbanization & & & $<0.05$ \\
\hline Provinces & 8777 (25.0\%) & 28167 (26.8\%) & \\
\hline Counties & $2568(7.3 \%)$ & 8464 (8.0\%) & \\
\hline Districts & 8988 (25.6\%) & $26504(25.2 \%)$ & \\
\hline Urban villages & $14753(42.0 \%)$ & $42123(40.0 \%)$ & \\
\hline Geography & & & $<0.05$ \\
\hline North & 18559 (52.9\%) & $52460(49.8 \%)$ & \\
\hline Central & $6502(18.5 \%)$ & $18653(17.7 \%)$ & \\
\hline South & $9151(26.1 \%)$ & 31605 (30.0\%) & \\
\hline East & $874(2.5 \%)$ & $2540(2.4 \%)$ & \\
\hline Income & & & $<0.05$ \\
\hline$<18000$ & $15880(45.3 \%)$ & 49785 (47.3\%) & \\
\hline 18000-35000 & 14363 (40.9\%) & 40763 (38.7\%) & \\
\hline$>35000$ & $4843(13.8 \%)$ & $14710(14.0 \%)$ & \\
\hline \multicolumn{4}{|l|}{ Co-morbidity } \\
\hline Diabetes & $1457(4.2 \%)$ & $2811(2.7 \%)$ & $<0.05$ \\
\hline Hypertension & $2472(7.0 \%)$ & $4467(4.2 \%)$ & $<0.05$ \\
\hline Hyperlipidemia & $1629(4.6 \%)$ & $2983(2.8 \%)$ & $<0.05$ \\
\hline Heart Disease & $2115(6.0 \%)$ & 3152 (3.0\%) & $<0.05$ \\
\hline Obesity & $91(0.3 \%)$ & $105(0.1 \%)$ & $<0.05$ \\
\hline \multicolumn{4}{|l|}{ Medication } \\
\hline Steroids & 19720 (56.2\%) & $24373(23.2)$ & $<0.05$ \\
\hline
\end{tabular}

controls. More than $50 \%$ of the asthma patients $(\mathrm{n}=19720$, $56.2 \%)$ used steroids as treatment for asthma.

On Kaplan Meier (KM) survival curve, two years would have produced significant CKD $(p<0.001)$ (Figure 1). Thus, a follow-up time of three years would have been more suitable in this study.

Subjects with asthma (2196 in 35086) were more likely have CKD compared to controls (4125 in 105258) (HR: 1.56, 95\% CI: 1.48-1.64; $p<0.001$ ) (Table 2).

After adjusting for sex, age, andco-morbidities, including obesity, patients with asthma developed CKD (HR: 1.13 [1.07-1.19], $p<0.001)$ compared to HR before the adjustments (HR: 1.56 [1.48-1.64], $p<0.001$ ) (Table 3). Male asthma patients were more likely to have CKD than female asthma patients (HR: 1.16 [1.11-1.22], $p<$ 0.001). Patients with co-morbidities, including diabetes mellitus (HR: 1.42 [1.33-1.51], $p<0.001$ ), hypertension (HR: 15.52 [14.18-16.99], $p<0.001)$, hyperlipidemia $(\mathrm{HR}=$ 1.55 [1.45-1.65], $p<0.001$ ), and heart disease (HR: 1.86 [1.71-1.98], $p<0.001)$, had high risks of CKD. Hypertension was the co-morbidity with the highest risk of developing CKD. After adjusting for steroid treatment, the adjusted HR of developing CKD was 1.40 in asthma subjects. Patients who used steroids had lower risk of developing CKD (HR: 0.50 [0.47-0.53], $p<0.001$ ).

Asthma patients taking steroids were compared to patients not taking steroids (Table 4). In the subgroup with steroid treatment $(\mathrm{n}=26236), 1038$ (3.96\%) developed CKD in the longitudinal follow-up within three years. In the subgroup without steroid treatment $(\mathrm{n}=8850), 1158$ (13.08\%) developed CKD in the same follow-up period. The HR of the steroid treatment subgroup was 0.56 (95\% CI: $0.522-0.61, p<0.001)$ after adjusting for comorbidities of diabetes mellitus, hypertension, hyperlipidemia, and heart disease. Steroid treatment attenuated the risk of developing CKD (HR: 0.56, 95\% CI: 0.62-0.61; $p<0.001$ ) after adjusting for co-morbidities (Table 5).

Non-steroidal drugs for treatment of asthma were grouped into five classes: expectorants, bronchodilators, anti-muscarinic agents, airway smooth muscle relaxants, and leukotriene receptor antagonists. After adjusting for co-morbidities, all of these drugs attenuated the HRs of developing CKD. Regardless of adjustments for co-morbidities and steroid use, expectorants and bronchodilators attenuated the risk for developing CKD.

\section{Discussion}

This prospective case control study analyzed the relationship between asthma and CKD (HR: 1.56 [1.481.64], $p<0.001$ ) using population-based data (LHID) in Taiwan. In the dataset, patients first diagnosed with asthma and without CKD between 2000 and 2003 were analyzed. The Kaplan-Meier survival curve showed a time-to-event of two years, such that patients with 


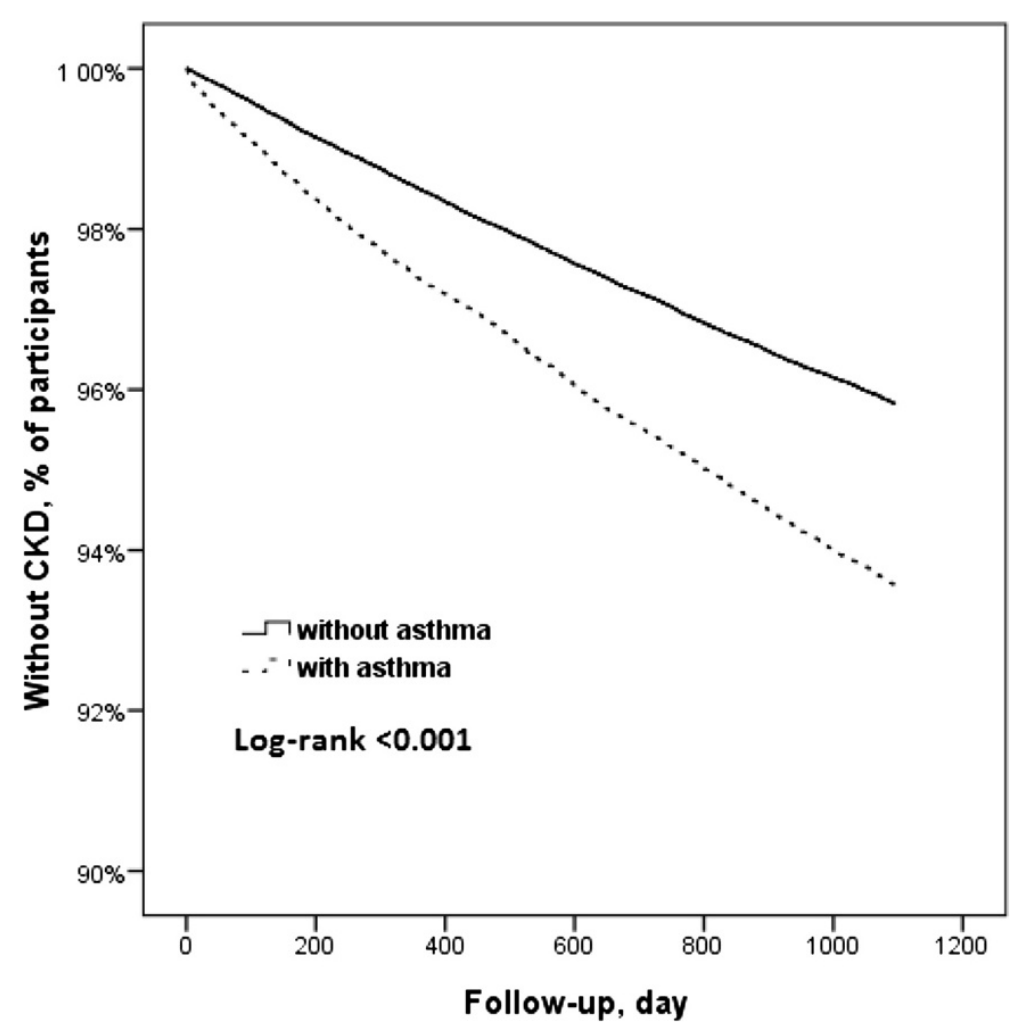

Figure 1 Survival curves of patients with and without asthma.

asthma would develop CKD in around two years $(p<0.001)$. As such, a follow-up time of three years was a sufficient follow-up period for this study.

Most researches report that patients with older age have increased risk of developing CKD [25]. Moreover, patients with hypertension [3], heart disease [4], diabetes [5], hyperlipidemia [9] and obesity [26-28] also have high risk of CKD. However, after adjusting for sex, age, and these co-morbidities, subjects with asthma still have significant and independent high risk of CKD (HR: 1.13 [1.07-1.19], $p<0.001)$.

Except for some rare case reports [29,30], there are very few studies investigating the interactions between asthma and CKD. To date, this is the first study to show that asthma patients are prone to developing CKD in

Table 2 Individuals with and without asthma as a predictor of chronic kidney disease, identified by Cox regression

\begin{tabular}{lcc}
\hline Characteristic & \multicolumn{2}{c}{ No. (\%) of individuals } \\
\cline { 2 - 3 } & $\begin{array}{c}\text { With asthma } \\
\mathbf{n}=\mathbf{3 5 0 8 6}\end{array}$ & $\begin{array}{c}\text { Without asthma } \\
\mathbf{n}=\mathbf{1 0 5 2 5 8}\end{array}$ \\
\hline With chronic kidney disease & 2196 & 4125 \\
Without chronic kidney disease & 32890 & 101106 \\
Hazard ratio & $1.56(1.48-1.64)^{\ddagger}$ & \\
\hline
\end{tabular}

${ }^{\ddagger} p<0.001$ for comparison between patients with asthma and the controls. comparison to non-asthma patients. Some patients with exercise-induce asthma seldom exercise [31] and several researches report that aerobic exercise may improve CKD $[32,33]$. Limited exercise may be one of the reasons for the higher risk of CKD in some types of asthma from the perspective of health behaviours.

Recently, one study of 2354 asthma patients from a retrospective cohort in China indicates that there is 9.6\% incidence of CKD in a period of six-year follow-up, in which the group of persistent asthma has independent, higher risk of CKD than the non-persistent group. In addition, patients with three traits together of long history of asthma $>20$ years, having no well-controlled asthma and persistent stage of asthma, have significant risk as high as $\mathrm{OR}=3.39$ (95\% CI 1.36-8.73), compared to patients without these traits [34]. This study finds an association between asthma and later CKD using a large cohort comprising asthma subjects $(\mathrm{n}=35086)$ and nonasthma controls $(\mathrm{N}=105258)$ in a three-year period of follow-up. Steroid and other medication treatment might decrease the risk of CKD associated with asthma. The suggestion of the two studies is similar that the value of well-controlled asthma is high not only to preserve the respiratory function but also to benefit other organs.

Furthermore, one common pathophysiology, inflammation, may provide some preliminary explanations. Recent 
Table 3 Independent predictors of chronic kidney disease, by Cox regression analysis

\begin{tabular}{lcc}
\hline Variable & $\begin{array}{c}\text { Adjusted } \mathbf{H R}^{*} \\
\mathbf{( 9 5 \%} \mathbf{C I})\end{array}$ & $\begin{array}{c}\text { Adjusted } \mathbf{H} \mathbf{R}^{* *} \\
\mathbf{( 9 5 \%} \mathbf{C l})\end{array}$ \\
\hline Asthma & $1.13(1.07-1.19)^{\ddagger}$ & $1.40(1.33-1.48)^{\ddagger}$ \\
Female & reference & reference \\
Male & $1.16(1.11-1.22)^{\ddagger}$ & $1.16(1.10-1.22) \neq$ \\
Age group & reference & reference \\
$18-29$ & $1.51(1.30-1.76)^{\ddagger}$ & $1.52(1.31-1.77)^{\ddagger}$ \\
$30-39$ & $1.91(1.66-2.19)^{\ddagger}$ & $1.99(1.73-2.28)^{\ddagger}$ \\
$40-49$ & $2.02(1.76-2.31)^{\ddagger}$ & $2.14(1.86-2.45)^{\ddagger}$ \\
$50-59$ & $2.08(1.83-2.38)^{\ddagger}$ & $2.23(1.96-2.55)^{\ddagger}$ \\
$\geq 60$ & &
\end{tabular}

Co-morbidity

Diabetes

Hypertension

$1.42(1.33-1.51)^{\ddagger} \quad 1.42(1.33-1.52)^{\ddagger}$

Hyperlipidemia

$15.52(14.18-16.99)^{\ddagger} \quad 15.24(13.92-16.68)^{\ddagger}$

Heart Disease

Obesity

$1.55(1.45-1.65)^{\ddagger} \quad 1.53(1.43-1.64)^{\ddagger}$

$1.84(1.71-1.98)^{\ddagger} \quad 1.92(1.78-2.06)^{\ddagger}$

$1.3(1.07-1.58)^{\dagger} \quad 1.39(1.14-1.69)^{\ddagger}$

Medication

Steroid (used in $56.2 \%$ asthma subjects)

Note: ${ }^{\dagger} p<0.05$ for comparison between patients with asthma and without asthma; ${ }^{\ddagger} p<0.001$ for comparison between patients with asthma and without asthma.

$H R^{*}$, each variable was adjusted for every other variable listed except for medication.

$H R^{* *}$, each variable was adjusted for every other variable listed.

advances in the study of leucine-rich repeat protein 3 (NLRP3) inflammasome may also provide a potential link between asthma and CKD. The NLRP3 inflammasome contributes to the progression of CKD by promoting renal inflammation [35] and plays a role in the human rhinovirus-related primary bronchial cell inflammation [36].

Table 4 Steroid use in patients with asthma as a predictor of chronic kidney disease, by Cox regression analysis

\begin{tabular}{lcc}
\hline Characteristics & \multicolumn{2}{c}{ No. (\%) of individuals } \\
\cline { 2 - 3 } & $\begin{array}{c}\text { With steroid use } \\
\mathbf{n = 1 9 7 2 0}\end{array}$ & $\begin{array}{c}\text { Without steroid use } \\
\mathbf{n}=\mathbf{1 5 3 6 6}\end{array}$ \\
\hline $\begin{array}{l}\text { With chronic kidney } \\
\text { disease }\end{array}$ & 1038 & 1158 \\
$\begin{array}{l}\text { Without chronic kidney } \\
\text { disease }\end{array}$ & 18682 & 14208 \\
Hazard ratio & $0.74(0.70-0.78)^{\ddagger}$ \\
Hazard ratio* & $0.56(0.53-0.589)^{\ddagger}$
\end{tabular}

Note: ${ }^{\ddagger} p<0.001$ for comparison between patients who used steroids and those who did not.

Hazard Ratio*, Adjusted for diabetes, hypertension, hyperlipidemia, and heart disease.
In our study, the recruited subjects with asthma are in older age as $47.72 \pm 17.73$ years. Several studies showed that asthma could develop at age after childhood, adolescence or young adult stage, and several genetic factors, air pollution or obesity could be related to later onset of bronchial asthma [37-39]. One study of 504 asthmatic patients (303 males and 201 females) in Taiwan indicates that 29\% developed asthma at age 25-44 years old, $21 \%$ developed asthma at age 45-65 years old, and 8\% developed asthma beyond age of 64 [40]. The recent study indicates that the age of onset asthma is $45.4 \pm 10.4$ years, which is also similar to our study of $47.72 \pm 17.73$ years [34].

Aside from co-morbidities, drugs used in the treatment of asthma also influence the development of CKD. These include steroids and non-steroidal antiasthma drugs. In this study, $56.2 \%$ of patients with asthma take steroids. Steroid use is associated with lower risk of CKD after adjusting for sex, age, and comorbidities. Steroids can decrease inflammatory reactions and are used to treat inflammatory diseases. After adjusting for steroid use, the HR of asthma increased, indicating that asthma directly impacts on CKD. This also supports the hypothesis that chronic inflammation in asthma patients may be related to the higher risk of developing CKD. Proper steroid treatment for asthma may significantly reduce the risk of CKD.

Non-steroidal drugs used for asthma were also analyzed. In this study cohort, only patients with asthma were included. Classes of non-steroidal drugs were expectorants, bronchodilators, anti-muscarinic agents, airway smooth muscle relaxants, and leukotriene receptor inhibitors. After adjusting for diabetes, hypertension, hyperlipidemia, and heart disease, all of these non-steroidal drugs could attenuate the development of CKD. Nonetheless, regardless of adjustments for comorbidities or steroid use, expectorants and bronchodilators can attenuate the risk for CKD. Although leukotriene receptors have anti-inflammatory properties, they have low potential of attenuating the risk for CKD [41]. However, the biological mechanisms involved warrant further investigations.

This study has some limitations. Although the LHID 2005 in Taiwan has benefits in analyzing disease and is commonly used in research because of its reliability, it has some limitations. First, the selected data might exclude samples because of missing data, making the data here incomplete. Second, the diagnostic code is made by doctors. However, sometimes the code is not final, especially in ambulatory settings. Third, the presence of diseases was base on ICD-9-CM. The precision of this system and its impact on outcome could not be determined. Furthermore, no information about cigarette smoking, which is a risk factor of CKD [42], is available in the NHIRD database. However, we have 
Table 5 Hazard ratios (HRs) of asthma patients by drug used compared to patients without drug use

\begin{tabular}{|c|c|c|c|c|c|c|}
\hline Variables & n (\%) & HR $(95 \% \mathrm{Cl})$ & $\mathrm{HR}^{*}(95 \% \mathrm{Cl})$ & $\mathrm{HR}^{* *}(95 \% \mathrm{Cl})$ With steroid & $\mathrm{HR}^{* * *}(95 \% \mathrm{Cl})$ Without steroid & $\mathrm{HR}^{* * * *}(95 \% \mathrm{Cl})$ \\
\hline \multicolumn{7}{|l|}{ Steroid } \\
\hline Yes $(n=19720)$ & $1038(5.3 \%)$ & $0.68(0.62-0.73)^{\ddagger}$ & $0.56(0.52-0.61)^{\ddagger}$ & N/A & N/A & N/A \\
\hline No $(n=15366)$ & $1158(7.5 \%)$ & & & & & \\
\hline \multicolumn{7}{|l|}{ Expectorant } \\
\hline Yes $(n=6818)$ & 339 (5.0\%) & $0.74(0.66-0.83)^{\ddagger}$ & $0.59(0.53-0.67)^{\ddagger}$ & $0.63(0.54-0.74)^{\ddagger}$ & $0.65(0.55-0.78)^{\ddagger}$ & $0.64(0.57-0.72)^{\ddagger}$ \\
\hline No $(n=28268)$ & $1857(6.6 \%)$ & & & & & \\
\hline \multicolumn{7}{|l|}{ Bronchodilators } \\
\hline Yes $(n=19933)$ & $1157(5.8 \%)$ & $0.84(0.77-0.91)^{\ddagger}$ & $0.67(0.61-0.72)^{\ddagger}$ & $0.78(0.68-0.89)^{\ddagger}$ & $0.78(0.69-0.88)^{\ddagger}$ & $0.78(0.71-0.85)^{\ddagger}$ \\
\hline No $(n=15153)$ & $1039(6.9 \%)$ & & & & & \\
\hline \multicolumn{7}{|c|}{ Anti-muscarinic agents } \\
\hline Yes $(n=4298)$ & $264(6.1 \%)$ & $1.00(0.88-1.14)$ & $0.72(0.63-0.82)^{\ddagger}$ & $0.87(0.75-1.01)$ & $0.86(0.64-1.14)$ & $0.87(0.76-0.99)^{\ddagger}$ \\
\hline No $(n=30788)$ & $1932(6.3 \%)$ & & & & & \\
\hline \multicolumn{7}{|c|}{ Airway smooth relaxant } \\
\hline Yes $(n=19222)$ & $1245(6.5 \%)$ & $1.07(0.99-1.17)$ & $0.75(0.69-0.82)^{\ddagger}$ & $0.88(0.77-1.02)$ & $0.91(0.81-1.03)$ & $0.90(0.82-0.99)^{\dagger}$ \\
\hline No $(n=15864)$ & $951(6.0 \%)$ & & & & & \\
\hline \multicolumn{7}{|c|}{ Leukotriene receptor antagonist } \\
\hline Yes $(n=1432)$ & $46(3.2 \%)$ & $0.48(0.36-0.65)^{\ddagger}$ & $0.59(0.44-0.79)^{\ddagger}$ & $0.72(0.52-1.00)$ & $0.62(0.32-1.20)$ & $0.69(0.52-0.93)^{+}$ \\
\hline No $(n=33654)$ & $2150(6.4 \%)$ & & & & & \\
\hline
\end{tabular}

Note: $\mathrm{HR}^{*}$, each factor was adjusted for diabetes, hypertension, hyperlipidemia, and heart disease.

$\mathrm{Cl}$, confidence interval; $\mathrm{n}(\%)$, number of participants with CKD and\% of participants.

${ }^{+} p<0.05$ for comparison between patients with asthma and without asthma; ${ }^{\ddagger} p<0.001$ for comparison between patient with asthma and without asthma.

Hazard ratios (HRs) of asthma patients by drug used. In each drug, the HR was compared with patients without drug. (a) Crude HR (95\% Cl) for each drug. (b) HR*(95\% Cl) for each drug, adjusted for co-morbidities.

(c) Patients with steroid HR **(95\% Cl) for each drug, adjusted for co-morbidities. (d) Patients without steroid use HR ***(95\% Cl) for each drug, adjusted for co-morbidities. (e) HR **** (95\% Cl) for each drug, adjusted

for co-morbidities and steroid use. 
adjusted other metabolic risk factors such as diabetes mellitus, hypertension, hyperlipidemia, and obesity.

\section{Conclusions}

Asthma patients have higher risk of developing CKD. Although interactions between asthma and CKD are still unclear, behavioural or biological factors such as limited exercise, inflammation, and other unknown factors can contribute to the interactions between asthma and kidney diseases. Steroids and some non-steroidal antiasthma drugs can attenuate this risk and the proper medical treatment for asthma may be beneficial in reducing the risk of CKD.

\section{Competing interests}

The authors declare that they have no competing interests.

\section{Authors' contributions}

NST conceived of the study, participated in its design and coordination, data interpretation and drafted the manuscript. HLH participated in the design of the study, data interpretation, performed the statistical analysis, data collection and drafting of the manuscript. SYH participated in the design of the study and participated in data interpretation. CHL participated in the design of the study, data interpretation and drafting of the manuscript. FYC participated in the design of the study, literature search, data collection, and performed the statistical analysis. LPC participated in data collection and data interpretation. HCL and WLC participated in the design of the study and data interpretation. All authors have read and approved the final manuscript.

\section{Acknowledgements}

This work was supported by National Science Council of Taiwan under the contract number NSC-101-2627-B-009-003, and "Center for Bioinformatics Research of Aiming for the Top University Program" of the National Chiao Tung University and Ministry of Education, Taiwan, R.O.C. for the project 102 W962. This work was also supported in part by the UST-UCSD International Center of Excellence in Advanced Bioengineering sponsored by the Taiwan National Science Council I-RiCE Program under Grant Number: NSC-101-2911-I-009-101.

Authors thank Ms Wei-Shan Jessie Chiang for her assistance in the administrative work and proofreading of the manuscript.

\section{Author details \\ ${ }^{1}$ Institute of Bioinformatics and Systems Biology, National Chiao Tung University, Hsinchu, Taiwan. ${ }^{2}$ Department of Biological Science and Technology, National Chiao Tung University, Hsinchu, Taiwan. ${ }^{3}$ Department of Surgery, Division of Neurosurgery, National Taiwan University Hospital Hsin-Chu Branch, Hsinchu City, Taiwan. ${ }^{4}$ Department of Psychiatry, Tri-Service General Hospital, School of Medicine and Student Counseling Center, National Defense Medical Center, \#325, Sec 2, Cheng-Gong RdNei- Hu District, Taipei City, Taiwan.}

Received: 31 October 2013 Accepted: 6 May 2014

Published: 8 May 2014

\section{References}

1. Masoli M, Fabian D, Holt S, Beasley R, Global Initiative for Asthma P: The global burden of asthma: executive summary of the GINA Dissemination Committee report. Allergy 2004, 59(5):469-478

2. Mueller NT, Koh WP, Odegaard AO, Gross MD, Yuan JM, Pereira MA: Asthma and the risk of type 2 diabetes in the Singapore Chinese Health Study. Diabetes Res Clin Pract 2013, 99(2):192-199.

3. Johnson M, Nriagu J, Hammad A, Savoie K, Jamil H: Asthma, Environmental Risk Factors, and Hypertension Among Arab Americans in Metro Detroit. J Immigr Minor Healt 2010, 12(5):640-651.

4. Iribarren C, Tolstykh IV, Miller MK, Sobel E, Eisner MD: Adult Asthma and Risk of Coronary Heart Disease, Cerebrovascular Disease, and Heart
Failure: A Prospective Study of 2 Matched Cohorts. Am J Epidemio/ 2012, 176(11):1014-1024

5. Ehrlich SF, Quesenberry CP, Van Den Eeden SK, Shan J, Ferrara A: Patients Diagnosed With Diabetes Are at Increased Risk for Asthma, Chronic Obstructive Pulmonary, Disease, Pulmonary Fibrosis, and Pneumonia but Not Lung Cancer. Diabetes Care 2010, 33(1):55-60.

6. Chen W, Liu Q, Wang H, Chen W, Johnson RJ, Dong X, Li H, Ba S, Tan J, Luo N, Liu T, He H, Yu X: Prevalence and risk factors of chronic kidney disease: a population study in the Tibetan population. Nephrol Dial Transplant 2011, 26(5):1592-1599.

7. Kawashima M, Wada K, Ohta H, Terawaki H, Aizawa Y: Association between asymptomatic hyperuricemia and new-onset chronic kidney disease in Japanese male workers: a long-term retrospective cohort study. BMC Nephrol 2011, 12(31). doi: 10.1186/1471-2369-12-31.

8. Zhang QL, Brenner H, Koenig W, Rothenbacher D: Prognostic value of chronic kidney disease in patients with coronary heart disease: Role of estimating equations. Atherosclerosis 2010, 211(1):342-347.

9. Post JB, Jegede AB, Morin K, Spungen AM, Langhoff E, Sano M: Cognitive Profile of Chronic Kidney Disease and Hemodialysis Patients without Dementia. Nephron Clin Pract 2010, 116(3):C247-C255.

10. Edwards NC, Ferro CJ, Kirkwood H, Chue CD, Young AA, Stewart PM, Steeds RP, Townend JN: Effect of Spironolactone on Left Ventricular Systolic and Diastolic Function in Patients With Early Stage Chronic Kidney Disease. Am J Cardiol 2010, 106(10):1505-1511.

11. Ooi QL, Tow FKNFH, Deva R, Alias MA, Kawasaki R, Wong TY, Mohamad N, Colville D, Hutchinson A, Savige J: The Microvasculature in Chronic Kidney Disease. Clin J Am Soc Nephro 2011, 6(8):1872-1878.

12. Ryoo JH, Kim SG, Suh BS, Kim DI, Park SK: Relationship between Chronic Kidney Disease and Risk of Coronary Heart Disease in Korean Men. J Korean Med Sci 2011, 26(6):753-758.

13. Ho Chan W: Taiwan's healthcare report 2010. EPMA J 2010, 1(4):563-585.

14. Chinese Hospital Association: ICD-9-CM English-Chinese Dictionary. Taipei, Taiwan: Chinese Hospital Association Press; 2000.

15. Bureau of National Health Insurance Regulations. http://www.nhi.gov.tw/ resource/bulletin/421_0890036465-19.doc.

16. Levey AS, Eckardt KU, Tsukamoto Y, Levin A, Coresh J, Rossert J, De Zeeuw D, Hostetter TH, Lameire N, Eknoyan G: Definition and classification of chronic kidney disease: a position statement from Kidney Disease: Improving Global Outcomes (KDIGO). Kidney Int 2005, 67(6):2089-2100.

17. Yeh KW, Chiang LC, Chen SH, Huang JL: Survey of the clinical practice of physicians in the management of asthma in Taiwan. Asian Pac J Allergy Immunol 2006, 24(1):1-8.

18. Yeh KW, Chiang LC, Huang JL: Epidemiology and current status of asthma and associated allergic diseases in Taiwan- ARIA Asia-Pacific Workshop report. Asian Pac J Allergy Immunol 2008, 26(4):257-264.

19. National Institutes of Health NH, Lung, and, Institute B: Diagnosis and classification. In Global Strategy for Asthma Management and Prevention. Bethesda, MD, USA: National Institutes of Health, National Heart, Lung, and Blood Institute; 2002:67-79.

20. Global Initiative for Asthma Program: Global Strategy for Asthma Management and Prevention: 2012 Update. http://www.ginasthma.org/ documents/5/documents_variants/37.

21. Lin LY, Lee CH, Yu CC, Tsai CT, Lai LP, Hwang JJ, Chen PC, Lin JL: Risk factors and incidence of ischemic stroke in Taiwanese with nonvalvular atrial fibrillation-A nation wide database analysis. Atherosclerosis 2011, 217(1):292-295.

22. Chiang YY, Lin HW: Association between psoriasis and chronic obstructive pulmonary disease: a population-based study in Taiwan. J Eur Acad Dermatol 2012, 26(1):59-65.

23. Chung SD, Lin HC: Increased Risk of Benign Prostatic Enlargement Among Patients With Liver Cirrhosis: A Nationwide Population-Based Study. J Androl 2011, 32(2):159-164

24. Lin HY, Lai Jl, Lai YC, Lin PC, Chang SC, Tang GJ: Acute renal failure in severe pancreatitis: A population-based study. Upsala J Med Sci 2011, 116(2):155-159.

25. Quon BS, Mayer-Hamblett N, Aitken ML, Smyth AR, Goss CH: Risk Factors for Chronic Kidney Disease in Adults with Cystic Fibrosis. Am J Resp Crit Care 2011, 184(10):1147-1152.

26. Wickens KBD, Friezema A, Rhodius R, Bone N, Purdie G, Crane J: Obesity and asthma in 11-12 year old New Zealand children in 1989 and 2000. Thorax 2005, 60(1):7-12. 
27. Lessard $A$, Turcotte $H$, Cormier $Y$, Boulet LP: Obesity and asthma: a specific phenotype? Chest 2008, 134(2):317-323.

28. Figueroa-Munoz JI, Chinn S, Rona RJ: Association between obesity and asthma in 4-11 year old children in the UK. Thorax 2001, 56(2):133-137.

29. Dubchak I, Gomolka M, Niemczyk S: Rapid course of Churge-Strauss syndrome-since appearance of asthma till development of renal failure and neurological complication. Pol Merkur Lekarkki 2012, 32(189):170-172.

30. Aarset $\mathrm{H}$, Aasarod K, Bergan $\mathrm{U}$, Angelsen A: Acute renal infarction in a woman with slight asthma. Nephrol Dial Transplant 2001, 16(8):1711-1712.

31. Small I, Moreira A, Couto M: Practical approach to managing exercise-induced asthma in children and adults. Prim Care Respir J 2013, 22(1):126-129.

32. Moinuddin I, Leehey DJ: A comparison of aerobic exercise and resistance training in patients with and without chronic kidney disease. Adv Chronic Kidney Dis 2008, 15(1):83-96.

33. Leehey DJ, Moinuddin I, Bast JP, Qureshi S, Jelinek CS, Cooper C, Edwards LC, Smith BM, Collins EG: Aerobic exercise in obese diabetic patients with chronic kidney disease: a randomized and controlled pilot study. Cardiovasc Diabetol 2009, 8:62.

34. Liu DW, Zhen XG, Liang Y, Jing XG, Zhang TS, Zhang GJ, Liu ZS: Persistent asthma increases the risk of chronic kidney disease: a retrospective cohort study of 2354 patients with asthma. Chin Med J (Engl) 2013, 126(21):4093-4099.

35. Vilaysane A, Chun J, Seamone ME, Wang W, Chin R, Hirota S, Li Y, Clark SA, Tschopp J, Trpkov K, Hemmelgarn BR, Beck PL, Muruve DA: The NLRP3 inflammasome promotes renal inflammation and contributes to CKD. J Am Soc Nephrol 2010, 21(10):1732-1744.

36. Triantafilou K, Kar S, van Kuppeveld FJ, Triantafilou M: Rhinovirus-Induced Calcium Flux Triggers NLRP3 and NLRC5 Activation in Bronchial Cells. Am J Respir Cell Mol Biol 2013, 49(6):923-934.

37. Jeebhay MF, Ngajilo D, le Moual N: Risk factors for nonwork-related adult-onset asthma and occupational asthma: a comparative review. Curr Opin Allergy Clin Immunol 2014, 14(2):84-94.

38. Le Moual N, Carsin AE, Siroux V, Radon K, Norback D, Toren K, Olivieri M, Urrutia I, Cazzoletti L, Jacquemin B, Benke G, Kromhout H, Mirabelli MC, Mehta AJ, Schlünssen V, Sigsgaard T, Blanc PD, Kogevinas M, Antó JM, Zock JP: Occupational exposures and uncontrolled adult-onset asthma in the European Community Respiratory Health Survey II. Eur Respir J 2014, 43(2):374-386.

39. Lee YL, Hsiue TR, Lee CH, Su HJ, Guo YL: Home exposures, parental atopy, and occurrence of asthma symptoms in adulthood in southern Taiwan. Chest 2006, 129(2):300-308.

40. Hsu JY, King SL, Kuo Bl, Chiang CD: Age of onset and the characteristics of asthma. Respirology 2004, 9(3):369-372.

41. Papierniak ES, Lowenthal DT, Harman E: Novel Therapies in Asthma: Leukotriene Antagonists, Biologic Agents, and Beyond. Am J Ther 2013, 20(1):79-103.

42. Noborisaka Y, Ishizaki M, Yamazaki M, Honda R, Yamada Y: Elevated Serum Gamma-Glutamyltransferase (GGT) Activity and the Development of Chronic Kidney Disease (CKD) in Cigarette Smokers. Nephro-urology monthly 2013, 5(5):967-973.

doi:10.1186/1471-2466-14-80

Cite this article as: Huang et al.: Bronchial asthma is associated with increased risk of chronic kidney disease. BMC Pulmonary Medicine 2014 14:80.

\section{Submit your next manuscript to BioMed Central and take full advantage of:}

- Convenient online submission

- Thorough peer review

- No space constraints or color figure charges

- Immediate publication on acceptance

- Inclusion in PubMed, CAS, Scopus and Google Scholar

- Research which is freely available for redistribution 